\title{
Another Visit to BE Supposed to from a Diachronic Constructionist Perspective.
}

"Take words in various senses, and all may be true that is contradictorily affirmed or denied concerning what they are supposed to signifie." (John Owen. The Doctrine of Justification by Faith. 1677)

The BE supposed to string has meanings ranging from expressions of assumptions, hearsay, expectations, weak obligation, predestination and, in the negative, prohibition. Several problems have been discussed previously with the historical development of the deontic senses, most notably that it appears to break the "deontic to epistemic" unidirectionality constraint in grammaticalisation (Traugott 1989, Zeigler 2003, Visconti 2004, Berkenfield 2006, Moore 2007). Noël and van der Auwera (2009) argued that the preceding accounts lacked support from the data and that SUPPOSE must have had an original intend' sense when it was borrowed. They illustrated the paper with examples from the OED. However, I show how the OED interpretations are incorrect; none of the active or early passive examples cited actually have deontic senses. I present a usage-based construction grammar account of the development, arguing that the deontic sense for BE supposed to arose when the form was re-interpreted as instantiating an existing passive deontic construction, licensed by analogy to the existing synonymy with $B E$ expected to. This was possible due to a process of metonymy, whereby part of the original meaning of the string, in particular usage-event contexts, becomes the whole meaning. The development may not in fact contravene unidirectionality constraints.

\section{Introduction}

The BE supposed to form has attracted some attention in the literature on language change. This paper discusses problems in the historical development of the construction exemplified in (1) and its relationship with that in (2). In examples like (1) the meaning is one of obligation, rather like should, and is deontic modality. ${ }^{1}$ However, the most frequent use in historical data is epistemic or evidential, as in (2), where BE supposed to can often mean 'assume/believe' with a hearsay function, or occasionally 'expect'.

(1) A girl is not supposed to ask for an introduction to a man, but--low be it spoken--she often does; (1903. Devereux The Etiquette of Engagement and Marriage.)

(2) There is a bridge ouer the sayde riuer, which is supposed to bee the fayrest that is in all the worlde $(1588 . \mathrm{a} 01864)^{2}$

\footnotetext{
${ }^{1}$ Palmer.

${ }^{2}$ Examples taken from the $E E B O-T C P$ are identified by their SGM filename in the format "a012345.
} 


\section{S. J. Disney}

On the surface, such polysemy is unproblematic; one sense emerges from the first, often by a process of metonymy, i.e. part of the meaning of a form becomes the whole meaning. ${ }^{3}$ However, the BE supposed to construction appears to have developed the deontic sense from the epistemic/evidential, which has been argued to break a unidirectionality constraint in language change. Specifically, constructions tend to develop from expressing deontic meanings to expressing epistemic ones and not vice versa. Further, the deontic has 'taken over' the form and is the most common BE supposed to use; in a random sample of five hundred instances from the British National Corpus (BNC) conversation data, recorded in the 1990's, deontic uses account for over half of all supposed tokens.

The changes to this construction have been described as an example of grammaticalisation, a well-established feature of language change, ${ }^{4}$ based on observed regularities, supported by cross-language data. ${ }^{5}$ There are several features that may act as heuristics for grammaticalisation, although none are conclusive. For example, linguistic lexical items may become more 'grammatical' over time; i.e. lexical words can become function words, and function words can become bound morphemes. The existence of unidirectionality in morphology in grammaticalisation is robust and it is rare that such a shift along the lexical grammatical continuum occurs in the reverse order. ${ }^{6}$

With respect to $\mathrm{BE}$ supposed to, the construction exhibits many features of grammaticalisation. Firstly, it is arguably no longer as lexical as the original active SUPPOSE; Quirk et al. consider deontic BE supposed to a semi-auxiliary, ${ }^{7}$ and for Biber et al. it is "semi-modal", ${ }^{8}$ i.e. it is somewhere between being a lexical and a grammatical item. Secondly, the construction has undergone some syntactic reanalysis, as demonstrated in (3). Formally, the reanalysis is that [supposed [to V]] becomes [[supposed to] $V]$ in the semiauxiliary use. The constituent structure in the former means that the complement verb cannot be deleted in (3A), whereas in $(3 \mathrm{~B})$, it can.
A) *He isn't nice even though he is supposed to _..
B) He isn't going even though he is supposed to _.?

As part of grammaticalisation, a construction may undergo semantic "bleaching"10 or "semantic reduction". 11 That is, the original form has a more concrete, lexical meaning,

\footnotetext{
${ }^{3}$ Croft and Cruse.

${ }^{4}$ Croft, Explaining Language Change; Hopper and Traugott, Grammaticalization.

5 See Bybee, Perkins, and Pagliuca, Evolution of Grammar; Heine and Kuteva, World Lexicon of Grammaticalization.

6 See Haspelmath, "Why Is Grammaticalization Irreversible?"; van der Auwera, "More Thoughts on Degrammaticalization"; Haspelmath, "Directionality in Language Change"; Rosenbach; Norde for discussion and possible counter-examples. This is also connected to the contiguity requirement in semantic maps of conceptual space; see Croft, Radical Construction Grammar.

${ }^{7}$ Quirk et al.

${ }^{8}$ Biber et al., 483.

${ }^{9}$ Note that in casual speech the pronunciation of these examples will differ. In (3A) type uses it is more like /səpa Ust tu/, while in the deontic it is reduced to /spəUstə/. Phonetic reduction is highly indicative of grammaticalisation, although it is not necessarily heuristic.
} 
whereas the more grammaticalised form has more abstract semantic content, that is often just a part of the original meaning. In examples like (1) and (3B), "X BE supposed to V" has a meaning similar to the modal expression "X should V". As such, this is unproblematic; lexical content like 'assume' and 'expect' seems more concrete than the resulting 'should'like deontic expression. However, the case with semantic change and unidirectionality is rather more debatable and there are two problems to discuss.

Firstly, meaning change between one sense and another typically occurs gradually, manifesting in historical data as "links on a chain"12. Yet, despite there being no shortage of examples, such links are difficult to establish for SUPPOSE. Secondly, as noted above, the development of an epistemic sense into a deontic one would break the "quasi-universal" deontic > epistemic grammaticalisation path ${ }^{13}$ and researchers have proposed different paths of development to account for this anomalous construction. ${ }^{14}$ The data presented in some of the previous papers are more problematic than they appeared and the conclusions based on them therefore need revisiting. This paper proposes an amended analysis in a usage-based, construction grammar perspective. The paper is structured as follows: In section two, I discuss examples from the literature. Section three presents examples from the available historical data, while section four describes the amended account of the development. Section five concludes the paper.

\section{The Cited History of SUPPOSE}

According to the Oxford English Dictionary Online $\left(O E D_{3}\right)$, the SUPPOSE lexeme in English dates from around 1300. It was borrowed from French supposer, (gloss: 'assume', 'hypothesise'), which in turn is derived from Latin supponere (=sub+ponere, literally under+place). Thus the Latin 'physical' sense gave rise to a 'mental' sense, which is an extremely common type of development in semantic change. ${ }^{15}$

The earliest examples of SUPPOSE in the $O E D_{3}$ are (4), from 1303, glossed as 'expect' and (5), glossed as "hold as a belief or opinion".

(4) Whan Seynt Ihon herde pat seye, pat Troyle supposed for to deye (R. BRUNNE Handl. Synne 6970)

"St. John heard it said that [Bishop] Troilus expected to die"

(5) We shuld trow, and suppose ay pat all er save (HAMPOLE Pr. Consc. 3776)

"We should always trust and believe that all are saved"

\footnotetext{
${ }^{10}$ See e.g. Traugott and Trousdale.

${ }^{11}$ Bybee, Perkins, and Pagliuca, 106-24.

12 Ibid., 17.

${ }^{13}$ Noël and van der Auwera, 599.

${ }^{14}$ See Noël and van der Auwera for discussion.

${ }^{15}$ Bybee, Perkins, and Pagliuca, Evolution; Heine and Kuteva, World Lexicon.
} 


\section{S. J. Disney}

The Middle English Dictionary includes the senses listed in (6), where (6e) is similar to the literal translation of supponere.
a. believe as a fact
b. anticipate, expect
c. take for granted, assume (without reference to truth or falsehood), posit, conjecture, hypothesize, guess, imagine,
d. suspect, allege, feign, speak deceptively
e. support, place support under

As the passive developed in English, treorting verbs started to be used in it, but the earliest example of a 'believe' sense for passive BE supposed to in the $O E D_{3}$ is as late as 1557 . However, the earliest I have found is (7), albeit a translation from French. The $O E D$ does not note the deontic type 'obligative' sense until its 1972-1986 supplement.

(7) Leoncius reherceth that Lichaon so fleyng as sayd is supposyd to be sued after of Iupiter and be put to deth. (The Recuyell of the Historyes of Troye, by Raoul Lefevre, Translated 1474 By W. Caxton)

"Leontius reports that Lycaon is said to have fled and is believed to have been chased by Jupiter and put to death."

Table 1 summarises the previous research and reconstructions on the construction. The term 'deontic' refers to the weak obligative 'should-like' use, although note that intentions are also a part of 'deontic modality'. In sum, depending on the paper consulted, SUPPOSE may have had one original meaning, ${ }^{16}$ two, ${ }^{17}$ or even three. ${ }^{18}$

Table 1 Proposed Developmental Paths for SUPPOSE

In the earliest paper, Traugott argues that there are "two coexistent paths of development" for BE supposed to, derived from two borrowed senses, i.e. 'believe, imagine, hypothesize' and 'expect'. ${ }^{19}$ Traugott cites (4) above from the $O E D_{2}$, to show that the 'expect' use was "associated with for to complements". ${ }^{20}$ I have found only two examples of the string supposed for to in the fifteenth century data; (8) aligns with Traugott's view, but (9) could as easily be read as 'thought/believed'.

(8) Sone after the woman came vpward ageyn and supposed for to haue entred within the chambre as she was accustomed to doo. $\left(1484\right.$. A18233) ${ }^{21}$

\footnotetext{
${ }^{16}$ Berkenfield; Moore; Visconti; Zeigler.

${ }^{17}$ Traugott, "Rise of Epistemic Meanings".

${ }^{18}$ Noël and van der Auwera.

${ }^{19}$ Traugott, "Rise of Epistemic Meanings", 46.

${ }^{20}$ Ibid., 56.

${ }^{21}$ Examples cited thus are taken from the Phase 1 release of the Early English Books Online Text Creation Partnership project (EEBO-TCP). See section 3 below for details.
} 
"Soon after the woman came upward again and expected to enter the chamber as she was accustomed to do."

(...) the Grekyssh knightes hadde taken lande seeing the grete dau ger that they had ben inne sprang oute of the shippe. whiche anone was fild full of water. And whan they sawe hem out of that mortall parill and had well supposed for to haue ben in sauete Sodaynly cam oute of Lennos the riche. (c.1470. a68341)

"the Greek knights landed, seeing the great danger that they had been in, an sprang out of the ship, which soon was filled full of water. And when they saw they were out of that mortal peril and had believed they would be safe, the nobles came out of Lennos."

Traugott says that the 'expect' sense "developed a deontic of intention", providing (10) as an example. $^{22}$

(10) Whan he sawe Alixandre he supposid to haue axid his requeste (1474. CAXTON Chesse II. i. (1883) 22)

"When he saw Alexander, he ?expected/?intended to ask his request."

In its original context, as translated from French by Caxton, it is quite indeterminate and could as easily be glossed 'expect', or 'attempted. Note that the deontic is nowhere claimed to have existed in French, and perhaps such a translation may be considered unlikely. However, such ambiguity is common with related words; for example, compare PDE presume something with presume to do something).

Visconti and Moore both argue that deontic BE supposed to derives from a contextually derived extension to the 'expect' meaning of passive supposed. ${ }^{23}$ As such there is little to choose between Traugott's dual source sense analysis and the views of Visconti and Moore. The critical point is that the paths from a single-source posited by Traugott, Ziegeler/Berkenfield and Visconti/Moore all run counter to the deontic > epistemic grammaticalisation path. Indeed, the conclusions below support the supposed counteruniversal path; however, the difference is that it was the construction BE supposed to as a whole that underwent the meaning change, not the form suppose/supposed as suggested in the previous accounts.

Visconti and Moore attempt to navigate around the unidirectionality problem by claiming that examples with a 'belief' sense are reportatives and therefore are evidential, not epistemic. Moore says a reportative has an evidential sense "since it indicates belief", ${ }^{24}$ which converges with Palmer. ${ }^{25}$ Berkenfield also distinguishes between lexical passives and an evidential use. ${ }^{26}$ However, Noël and van der Auwera make some convincing arguments in their

\footnotetext{
${ }^{22}$ Ibid., 46.

${ }^{23}$ Visconti; Moore.

${ }^{24}$ Moore, 118.

${ }^{25}$ Palmer.

${ }^{26}$ Berkenfield.
} 


\section{S. J. Disney}

rejection of the previous studies. ${ }^{27}$ They make a clear distinction between epistemic modality and evidentiality, but argue that this does not "safeguard" the unidirectionality hypothesis because the deontic is a "content" use, while the evidential is "non-content", i.e. it does not express "real-world" relationships. ${ }^{28}$ The development evidential > deontic is then counter to the broader "content $>$ non-content" grammaticalisation path. They therefore reject the previous reconstructions and argue instead that the source of deontic BE supposed to is an active deontic sense of SUPPOSE dating from when it was first borrowed and thus that there is no directionality problem; they argue that the later change is an example of the volitive > deontic path attested in a range of languages. ${ }^{29}$ One initial criticism of this view might be that positing a multiple-sense borrowing may not in fact rescue the universal grammaticalisation path, but may merely push the problem further back in time, bearing in mind the meaning of the original Latin of 'under' + 'to place' as noted above.

There are several points to discuss here and the starting point is to show how the supporting examples from the $O E D_{3}$ used by Noël and van der Auwera ${ }^{30}$ have been misconstrued. For the sake of completeness, I reconsider all their main examples, starting with the three actives, which they claim have a "clear" 'intend' reading. ${ }^{31}$ The first, example (11), is a personal letter expressing sympathy and a wish that the addressee's health is improved. The problem here is that the OED has altered the source text. The original has a comma, not a full stop, before I suppose and it should be as (11B).

A) I rather suspect that you do not allow yourself sufficient air and exercise; the physicians call them Non-naturals. I suppose to deter their patients from the use of them.' (1788. W. COWPER Let. 19 June [1982] III. 181)

B) I rather suspect that you do not allow yourself sufficient air and exercise; the physicians call them Non-naturals, I suppose to deter their patients from the use of them.'

This change obscures the parenthetical nature of suppose, which is a discourse marker in this context. The original clearly has an 'assume' reading and to deter is purposive, i.e. 'in order to deter', i.e. it has an equivalent function to modern English "I guess". It is also unclear how the author could 'intend' to deter someone else's patients from an action in any case.

The other two active examples cited are less obviously misconstrued than (11). Although a 'hope', 'desire' or 'intend' sense is not infeasible, it is perfectly possible, and unproblematic, to assign an 'expect' sense to SUPPOSE in both (12) and (13).

\footnotetext{
${ }^{27}$ Noël and van der Auwera.

${ }^{28}$ Sweetser.

${ }^{29}$ Noël and van der Auwera.

${ }^{30}$ Ibid.

${ }^{31}$ Ibid., 608.
} 
(12) King Augustus with their main Army had begun to draw a Line from Grypsswald to Trebeses, ... by which he supposed to pin up the Swedish Army in Straelsund. (1715. Hist. Wars Charles XII. King of Sweden 366)

(13) Adversite: pe lord pat I serue is to me a tiraunt. Reason: if pou suppose to wynne ought of his daunger, let hope be pi mynstrelle (c.1425 Dialogue between Reason and Adversity)

'Adversity: to me the lord I serve is a despot. Reason: if you intend to gain some of his power, let hope be your servant.' (Gloss provided by Noël and van der Auwera) ${ }^{32}$

While one cannot be sure precisely what the meaning was to the original writer/reader, in historical reconstructions, in principle, it makes no sense to posit problematic senses where unproblematic ones suffice. In my own reconstruction below, I follow such a 'conservative bias' in the methodology. In fact, data from the EEBO-TCP collection of texts reveals very few even indeterminate examples; for example in 2,824 tokens of supposed from just one decade (1650-59), with a frequency rate for active SUPPOSE of 43.7 per million words, only example (14) even comes close to a possible 'intend' use.

(14) By which [process] they supposed to separate gold by this way into a subtile, spiritual, and elementary power, each one a part; [and] afterwards by circulation and rectification to couple them again into one, but in vain; (1659. a28633)

Again, I see no reason why this too cannot be read as an unproblematic 'expected' example; an expectation concerns a future event that the agent believes will happen, and it is likely that the alchemists were quite certain of their success at this time. I would add that although both the $M E D$ and the $O E D_{3}$ cite 'intend' as a meaning for active suppose, they were not subject to having to consider constraints suggested by unidirectionality in language change and perhaps some classifications need to be treated with a little caution. Nonce examples can of course occur in data, but where an alternative and more common gloss is possible, there needs to be a very good reason for preferring a different, more problematic one.

While no supporting discussion was provided for examples (12) - (14), Noël and van der Auwera argue that even if 'intend' uses of active SUPPOSE are rare, "we cannot simply brush them aside". ${ }^{33}$ They add that we cannot "insist there is no relation between them and the almost equally rare early deontic examples of the passive pattern." They go on to discuss three $\mathrm{OED}_{3}$ sourced examples of early 'obligation' type uses, but these examples have been even more obviously misclassified by the $O E D_{3}$. In (16) only the final turn in the conversational snippet is supplied and as such it does indeed read like a deontic; it would be appear to be an instruction, supported by virtue of its being in a manual.

(15) Upon this line I make a pricke, which is the very station where the instrument is supposed to stand. (1607. J. Norden Surveyors Dialogue)

\footnotetext{
${ }^{32}$ Noël and van der Auwera.

${ }^{33}$ Ibid., 609.
} 


\section{S. J. Disney}

However, the full context in (16) shows it is not an instruction to do something; is supposed to is reporting an assumption relating the position on the map to the position on the ground. Perhaps an aspect mismatch has contributed to the misreading; in PDE this might be is supposed to be standing.

(16) SUR: Then I pray you, let me haue one to goe before me, alwaies to stand with a marke at (e)uery angle.

BAY: There is one gone.

SUR: I see him: Loe, I stirre not the table, now it is truly rectified, and vpon this line I make a pricke, which is the very station where the instrument is supposed to stand. (1607. a08310)

Such problems are not unusual; out of context, example (17) could also be construed as having a deontic 'obligative' sense. However, in PDE, the infinitive would be glossed as a perfect, i.e. was supposed to have been done, disallowing a deontic reading.

(17) [...] wyche murder was supposed to be done by a knyght called Tanguyde de Chastell (1533. a00525)

Noël and van der Auwera's next example ${ }^{34}$ also reads like a deontic, out of its context:

(18) Every man that lives under a law is supposed to be knowing of it. (1659. Burton's Diary (1828 IV. 480)

But the extended context once more disambiguates it; the subject, every man, is 'assumed' to know of the laws, and is not 'obliged' to.

(19) It is not once moved, that the power shall be in the single person. Farewell magistracy, and all rule and government! Men must therefore have no trust. This takes in pieces your whole form. Any gentleman may recite the Declaration. If I quote an author, must I bring the book, and desire you to read it, if it be so? Every man that lives under a law is supposed to be knowing of it. I much fear you have not leisure, actually, in a Grand Committee, to determine this.

The $O E D_{3}$ has also misread (20), Noël and van der Auwera's final supporting example. ${ }^{35}$

(20) You are not supposed to be very gracious among those who are most able to hurt you (1727 SWIFT let to Writer of Occas. Paper Wks 1778 XI 129.)

In fact, a deontic reading here does not even make sense and the extended context is not even needed for disambiguation; Swift is writing to warn the recipient that these people do not consider him 'gracious'. If this were advice, like a negative deontic should sense, it would surely be the other way around, i.e. one should be gracious when among those most able to hurt one. The reading is therefore that "You are not thought to be very gracious [...]"

\footnotetext{
${ }^{34}$ Noël and van der Auwera.

${ }^{35}$ Ibid.
} 
The modal system itself is mot unproblematic when it comes to classifying cases; for example, if (12) - (14) are glossed 'hoped' or 'wished', then they are desideratives, which can be categorised under a broader 'deontic modality'. Note that desires may form felicity conditions for imperatives and obligations; that is, if I ask or tell you to do something, this implies that I want you to do it. A desiderative is also possible by inference from an 'expect' sense: one may expect to get everything one wishes for, especially where there is a power imbalance in the discourse context. For example, a desire expressed by an authority could be construed as an instruction for that desire to be realised. This is a connection that I revisit in section 4 below.

Bearing in mind that (12)-(20) are the 'best' examples, and that no claim is made that French or Latin have had deontic values for the borrowed word, it seems more logical and far more likely, if more problematic, that the weak obligative sense did develop independently in English and that this is counter to the supposed universals in language change.

\section{Original Reconstruction}

This section presents a discussion on the best examples found in the data, in order to ascertain how and when the deontic BE supposed to construction may have developed.

\subsection{The data}

Views on this construction in the linguistics and grammaticalisation literature to date have been informed by only the OED or small corpora, like ARCHER and have attempted to generalise a complex historical development from these limited resources. The fact that the $O E D$ in particular has made so many errors on this particular construction led to the need for a more extensive dataset than previously used. A summary of the data is presented in table 2 below. Phase one of the Early English Books Online project by the Text Creation Partnership (hereafter EEBO-TCP) digitised a huge collection of texts dated from 1460-1699, with a few that fell into the early eighteenth century. The collection contains over five hundred million words of texts and since 1/1/2015 is freely available in the public domain. Many of the texts, especially the early ones, are translations, and there are some errors due to the machine reading of original texts. There are also numerous repetitions of texts. However, because these account for such a small proportion in the supposed to data, around one example per thousand, such examples were easily manually excluded.

Table 2 Distributions of realisations of SUPPOSE in the corpora. ${ }^{36}$

In sum; in the 350 years to 1720 , in over $500,000,000$ words and over 11,000 tokens of (BE) supposed to in the EEBO data, no deontic examples of BE supposed to were found, although

\footnotetext{
${ }^{36}$ The EEBO-TCP (part 1) SGM files were accessed at Lancaster University. The ECCO-TCP data used was the xml version available at http://www.textcreationpartnership.org (checked 8 July 2014).
} 


\section{S. J. Disney}

some are difficult to classify and discussed below in the interests of completeness. The construction seems to have developed after the period covered by the main (pre-1700) body of the EEBO-TCP. Therefore the analysis also discusses examples from the eighteenth and nineteenth centuries sourced from the ECCO-TCP and an original compilation of texts from various sources which were written between 1700-1799 (labelled herein C18C). ${ }^{37}$ The sheer volume of texts ensures a certain comprehensiveness, although I note that the data are in no sense 'balanced' as a corpus of linguistic samples should be.

Table 2 presents the data as totals per million words to provide a rough comparison of frequencies. ${ }^{38}$ Major orthographic variants of $\mathrm{BE}$ supposed to were extracted from the corpora listed in table 2 using Wordsmith Tools 5.0. This includes examples with intervening material of up to three words, e.g. adverbs or direct objects, between supposed and to, e.g. I supposed him to be [...]. The results were manually checked to eliminate false hits and are organised for convenience into fifty year periods (except 1460-99, the start of the EEBOTCP). In total, there are 115,777 tokens of SUPPOSE, 38,764 of supposed and 13,274 supposed to. There are 11,448 passive supposed to tokens including examples without BE, as occur in relative clauses for example. Generally speaking, all forms peaked in the late eighteenth century and all fell in the early nineteenth century. In fact, 1650 onwards, supposed to mostly occurs in the passive, at a rate of around $85-90 \%$ and it also is roughly a third of all tokens of supposed. Frequency rises of particular patterns are strongly indicative of grammaticalisation in progress and higher frequencies of use is likely to result in an increase in occasions of indeterminacy.

\subsection{Discussion of examples}

In the EEBO-TCP, an 'assume/believe' sense, with the passives best paraphrased as "is understood", is by far the most frequent, although there are a few active 'expect' examples, such as (21), the sole example in these data before 1500 .

Arieng marched forth acompanyed of his accomplices al armed to the place where he supposed to finde appollo (c.1470. a68341)

"Arieng marched on, accompanied by his armed accomplices, to the place where he expected to find Apollo"

There are many problems to consider in assigning meaning in context for (BE) supposed to in the historical data, particularly where the passive is concerned, and as noted above already

\footnotetext{
${ }^{37}$ This consists of 18,222,125 words from a range of text types written in the eighteenth century from the following sources: Project Gutenberg (c.50\%), EEBO (c.25\%), The Corpus of English Dialogues, the Lampeter Corpus and those Chadwyck Healey nineteenth century fiction texts that were actually written in the late eighteenth century.

${ }^{38}$ However, note that the range of text types is not in any sense 'balanced' in a Corpus Linguistics sense, so frequency data should be treated with caution. Indeed the corpus design has affected the results somewhat. For example, before 1800, the data are largely non-fiction, while the Chadwyck Healey corpus is entirely fiction. Because of this there is a high narrative use of suppose $(d)$ in the latter that does not occur in the former. I note that the frequency rise in the nineteenth century is entirely due to this.
} 
attested meanings are preferred over 'new' meanings in indeterminate cases. A good example of this is (22).

The Iewes supposed to shut GOD vp within their Temples (1583. a1698)

Bearing in mind variability in other areas of the language system at the time, e.g. tense / aspect and complementation patterns, this probably meant to the writer that the Jews 'supposed/believed they had shut...'. Such an interpretation should be preferred over one that posits a 'new' sense on the basis of a parallel with a similar pattern in PDE, especially where the PDE pattern also differs in expressions of aspect.

Consider also the indeterminacy in (23); from a PDE perspective both the senses are available for the interpretation, perhaps even simultaneously, yet for the original speaker it is most likely to be an 'assumed/believed' meaning because he is discussing interpretation, and not the writer's intention.

Take words in various senses, and all may be true that is contradictorily affirmed or denied concerning what they are supposed to signifie. (1677. a53686)

However, the fact that a given example may have a deontic reading to a modern eye may reveal an underlying conceptual link. This is one way in which potential 'switch' and 'bridging' contexts arise between new and old meanings. Switch examples are said to predate "bridging contexts", which are more obviously indeterminate and either the old or new meaning could be the one being expressed. In this light, a picture is being described in (24) and instructions are being given about how to make a cider press. The sense of supposed to is 'assumed', but there is arguably a tension here between what is "assumed to be so" and a "requirement" for it to be so.

(24) The Hopper, made tapering towards the bottom, in which you fling the Apples, and supply them as they sink towards the Cylinders. Note, That such another Hopper is suppos'd to be also made, and fitted to this fore-part of the Press, but here omitted, that the prospect and description of the Cylinders may the better be laid open and demonstrated. (1670. a38807)

Part of the cause of the indeterminacy in BE supposed to examples is the absence of an agent. Generally examples of BE supposed to do not have agentive by phrases; in a random sample of five hundred examples from the full BNC, none were found. Across passives in general, one finds 5-10\% have by-phrases. ${ }^{39}$ Agents can be omitted for a number of reasons; the agent may be known, obvious, or unimportant. With reporting verbs, it can be omitted where it is the 'general population' or an understood subset of it, e.g. experts and such a lack allows a 'hearsay' interpretation to emerge. This allows a hearsay reading to arise in the reportative passives, but unlike many passive deontic verbs in the same pattern, e.g. obliged and

\footnotetext{
${ }^{39}$ See Noël, "Passive Matrices" for discussion and frequencies of the English Passive Hearsay Construction and Xiao, McEnery and Qian, for frequencies on the passive in general.
} 


\section{S. J. Disney}

required, the BE supposed to construction simply does not allow any overt agent at all. This alone can cause some indeterminacy, e.g. compare (25), without an agent and the original (26) with one.

(25) Whereas every Free-born Subject of England is supposed to be present in Parliament and thereby is presumed to consent to all things that passe in Parliament.

Whereas every Free-born Subject of England is supposed to be present in Parliament, by the Knights or Burgesses of the place where he liveth, and thereby is presumed to consent to all things that passe in Parliament: (1659. a32921)

In semantic language change, one typically finds examples that are somewhat indeterminate between 'old' and 'new' senses. There are two stages that a form can go through as it changes meaning; "switch contexts", where the 'new' use emerges, perhaps as a nuance or a conversational implicature. ${ }^{40}$ Examples (25) - (26) predate by one hundred and fifty to two hundred years the first true examples of the deontic in my data. However, while no deontic meaning is expressed, certainly there is potential for a deontic inference to be drawn by the hearer in some cases. Consider (27) - (28) below, where a supposition potentially reads like the description of an obligation.

(27) How prove you that the Parents may not be prime covenanters, or Sponsors for their own Children? Are not they obliged to get Godfathers and Godmothers for them? who are supposed to come by their procurement? And doth not that signifie their own consent, to what these are to undertake (1689. a26924)

(28) Now the Bishops, who are always supposed to incline to Mercy rather than Severity, may perpetually, with a good Conscience, hinder the passing such a Bill as shall punish a Delinquent with Death who had not capitally offended before. (1682. a51395)

If these are examples of the bridging context, it is interesting to note that both are relative clauses. Berkenfield's solution is that such syntactic contexts are in fact the antecedents of the deontic construction. ${ }^{41}$ The data overall do not support this view, ${ }^{42}$ but it is possible that they may have contributed to the ambiguity in some usage events, and therefore formed part of the bridging context.

The best examples of early bridging contexts in the EEBO-TCP are (29)-(30), which concern regulations and rules, but an 'assumed' or 'expected' meaning is probable.

(29) I Answer, You must take in all; because they are supposed to live not after the flesh but after the spirit; but if it can be suppos'd that ye can live after the flesh, then ye die, as in the Text; (1684. a51846)

\footnotetext{
${ }^{40}$ Heine, 85.

${ }^{41}$ Berkenfield.

${ }^{42}$ Disney, "Evidentiality".
} 
this Law of Opinion and Reputation, as it is made to Constitute a distinct Law, is not well grounded, for a Law is always suppos'd to bring men under an obligation. (1699. a49317)

The context is critical in other ways as well. For example, Fischer argues that the use of close synonyms was a stylistic device, motivated by regard for symmetry in prose, i.e. it is an iconic reduplication feature. ${ }^{43}$ In (31)-(32) SUPPOSE is co-ordinated with hope and required respectively, which are "deontic". This could be evidence for a deontic sense of supposed, but it is not at all easy to firmly determine whether this is a case of synonymy or if there is a contrast. Bearing in mind the fact that BE supposed to did develop such a sense, the questions that these co-ordinated examples give rise to are not inconsequential.

(...) there was another New Oath preparing, which they both supposed and hoped most of the Clergy would not take (1694. a60955)

All Parents are supposed and required to be themselves the choosers of the Sponsors. (1673. a26892)

I suggest that in (31), the word both suggests a contrast exists, while in (32), rhetorical style may be unlikely to be strong motivating factor in an official notice. I would argue that supposed here means 'expected' or 'assumed', and is not a synonym of required. Positing a deontic value for supposed here is certainly unnecessary, and the 'conservative bias' in the methodology therefore applies. Even so, examples (31)-(32) are the closest to having a deontic sense in the seventeenth century data and the situation hardly changes through the eighteenth century data. In (33), two examples of BE supposed to appear in consecutive sentences.

(33) Next let him observe in what manner, and in what degree the beauty of this horn is increas'd, in fig. [57] where it is supposed to be bent two different ways. And lastly, let him attend to the vast increase of beauty, even to grace and elegance, in the same horn, fig. [58] where it is supposed to have been twisted round, at the same time, that it was bent two different ways, (as in the last figure.) (1753. William Hogarth The analysis of beauty.. ECCO-TCP K021626)

To a modern day reader, the first might read as a deontic and the second as an 'assumed' use. The indeterminacy here is due to the complements: there is an infinitive BE in the first and a present perfect in the second. But the perfect in the mid-eighteenth century did not have the same semantics as it does in present day English. On reflection, if one is able to suppress the urge to interpret the first example in (33) as deontic, the meaning is clearly the same in both examples. It would seem to me that the very fact of this identical use for the two forms, which a PDE speaker would probably avoid, is further evidence that the deontic BE supposed to construction had not developed at this point. ${ }^{44}$ Disney discusses many examples of the 917

\footnotetext{
${ }^{43}$ Fischer, "Cognitive Iconic Grounding", 55-82.

${ }^{44}$ Moore (2007: 118) notes a fall in frequency of BE supposed to in between the $18^{\text {th }}$ and $19^{\text {th }}$ centuries and argues it was due to an avoidance strategy, i.e. that increasing indeterminacy caused communicative difficulties
} 


\section{S. J. Disney}

tokens of BE supposed to in the $\mathrm{C} 18 \mathrm{C}$ data, that are potentially indeterminate, but as above, a deontic meaning was 'analysed away' in all cases as unnecessary or very unlikely. ${ }^{45}$

The ECCO-TCP data are very similar; as indeterminate as they may appear, (36)-(37) should both be read as 'assumptives' and not weak deontics. The latter is another case where variation with respect to the perfect is the root of the interpretation problem. I would add that there are no optative or desiderative examples in the eighteenth century data either.

(34) It was but a very few days since the wealth and power that should have raised me, far above the sphere of the Mowbray family, were supposed to be within my grasp. How painful was the distance at which they now appeared! (1794. Thomas Holcroft The adventures of Hugh Trevor.)

(35) And should he, by an impression on the minds of his creatures, think fit to impart to them some event hid in the shades of time yet unborn, to whom would the secret be revealed by immediate inspiration? The opinion of ages will answer this question to reverend old men, to people distinguished for eminent piety. The oracles of old were thus delivered by priests dedicated to the service of the God who was supposed to inspire them. (1792. Mary Wollstonecraft $A$ vindication of the rights of woman: with strictures on political and moral subjects.)

The closest to 'first' deontic examples are presented below, but even here, the meaning is not conclusive. Example (36) may be another case where PDE would have a perfect, i.e. it is supposed to have been summer, but it is the closest yet to being a 'proper' bridging instance and the meaning seems indeterminate between 'presumed' and 'intended'.

(36) 'The only thing I donot thoroughly like is, that she seems to be sitting out of doors, with only a little shawl over her shoulders and it makes one think she must catch cold.' 'But, my dear papa, it is supposed to be summer; a warm day in summer. Look at the tree.' (1816. Jane Austen Emma.)

In (37), from the same text, duties and obligations are the topic of the conversation, which helps the potential for a 'deontic' interpretation somewhat, as does the expression of instructions and obligations in a copular + to infinitive construction such "she is to smile". I also note the use of deontic expected in the context, which is, as I shall argue in line with Traugott, part of the story of the deontic extension of BE supposed to. ${ }^{46}$

In marriage, the man is supposed to provide for the support of the woman; the woman to make the home agreeable to the man; he is to purvey, and she is to smile.

and people avoided the offending constructions. Although this appears sound in terms of Gricean pragmatic maxims, the argument is not particularly convincing here, because there was a decrease in use of the evidential NCI as a whole at that time (Noël 2001). I note later that there was a corresponding rise in the use of deontic verbs in the NCI as well. This is yet more evidence against treating constructions in isolation.

${ }^{45}$ Disney, "Evidentiality and Modality".

${ }^{46}$ Traugott, "Rise of Epistemic Meanings". 
But in dancing, their duties are exactly changed; the agreeableness, the compliance are expected from him, while she furnishes the fan and the lavender water. (1816. Jane Austen Emma.)

These examples are early outliers and no others occur in the data for some thirty to forty years. Interestingly, it has been noted how editors of the time complained that Austen's style was too colloquial, and as a result her work was heavily edited. ${ }^{47}$ It is claimed that she was close to writing real conversation which is "a voice you're perhaps not hearing again until the early $20^{\text {th }}$ century" ${ }^{48}$ It may be no coincidence at all that higher frequency of BE supposed to in the written data did indeed occur at the start of the twentieth century, so it may be that Austin was an early adopter. Note that Krug shows how it can take thirty to fifty years for a change that started in spoken language to appear in higher register written data, aside from drama texts and poetry. ${ }^{49}$ This is strong support for the view that Austin was at the vanguard of the change in meaning of BE supposed to.

In the nineteenth century USA (sourced from the COHA collection of texts), the situation is exactly the same; infinitive complements where PDE might have a perfect aspect create potential bridging contexts, but there are no deontic examples of BE supposed to. The best illustration of indeterminacy I have found is (38), but the meaning of was supposed to is clear once one has read the following sentence, which contains an example of suppose.

That time which the married clergyman devotes to the care of his family, was supposed to be given up to the duties of charity and exercises of religion. If the testimony of Catholic writers may be relied on, these were much more regularly performed than we have been led to suppose. (1829. The North American Review. vol XXIX p. 270)

To return to the British $19^{\text {th }}$ century data, the next deontic-like example in the Chadwyck Healy Fiction data is (39), some twenty five years after (37); I think that this does have a clear deontic 'expected/obliged' meaning. Indeed, it is very difficult to see how the assumed or believed meaning of SUPPOSE would work here.

(39) Here, as in a theatre, the orchestra is supposed to play something melodious. (1840. William Makepeace Thackeray Catherine: A Story.)

The negative (40) is even more clearly deontic, but even here, there is hint of ambiguity between what is 'required behaviour' and what is 'assumed behaviour'. Use of must in the following statement strongly suggests that BE not supposed to is indeed a prohibitive here, however.

\footnotetext{
${ }^{47}$ Sutherland, "News Story".

${ }^{48}$ Sutherland, "Interview".

${ }^{49}$ Krug.
} 


\section{S. J. Disney}

(40) No, certainly not. Remember, we are not supposed to question the men's honest intentions towards us. We must appear utterly ignorant. (1878. William Clark Russell The Wreck of The Grosvenor.)

The conclusion that can be drawn from these examples is that the weak obligation (deontic) BE supposed to was innovated in the UK sometime before Austen's use in 1816 and that it had conventionalised and spread to a great extent by c.1860. Perhaps it was fashionable in some circles at that point and remained fairly colloquial; for example there are no examples of deontic BE supposed to in either the eighteenth or nineteenth century The Times newspaper archives.

The relative lack of really clear deontic BE supposed to examples in these data until the end of the nineteenth century and the turn of the twentieth century may be due to genre; the sources used are not concerned with instructions or duties. However, modern fiction and drama texts do have a distribution similar to spoken data, as evidenced in the $\mathrm{BNC},{ }^{50}$ so the fiction data would appear a sound choice. I noted above that the (potential) switch context examples are from religious, legal and government texts, i.e. social domains concerned with deontic fields of endeavour such as duties and obligations. In light of this, I looked outside the collections of data at six etiquette guides from the UK and USA with around forty years separating them. Such guides are explicitly concerned with instructions on required behaviour and are prototypically 'deontic' in their modality. The result was startling; no examples of BE supposed to in these books are deontic before 1900, while half of those from the early twentieth century etiquette guides are, e.g. (1) above. Note that the OED does not note the use until the late twentieth century. The compilers of the first edition may have not come across it or may have considered it an un-noteworthy dialect feature. They may even have rejected the use for inclusion on prescriptive grounds; it is impossible to know for sure. I would add, however, that the lack of examples in guides to behaviour in high society might add weight to the last point. Indeed, it has been shown elsewhere how the newly developing 'hearsay' use of the closely related BE meant to construction was used by younger people, but rejected by writers with an older high social status readership. ${ }^{51}$

All of this evidence suggests that the construction was innovated at the end of the eighteenth century, although only complete data can give a complete picture. The development involves a period of indeterminacy and ends with two potential interpretations for the BE supposed to form. The existence of switch contexts, as described above, is crucial because it means that the concepts are linkable. The development of BE meant to ${ }^{52}$ in the other direction as it were shows that a bridge is possible between these senses, despite supposed universal constraints on the direction of travel over the bridge.

\section{Discussion}

\footnotetext{
${ }^{50}$ Disney, "Evidentiality".

${ }^{51}$ Disney, "Reputed Sense of BE Meant To".

${ }^{52}$ Ibid.
} 
The goal here is to show how, in a usage-based perspective, the development of the deontic BE supposed to construction could have arisen. The result is the observed polysemy in PDE, but it is not this end result that needs to be explained; the focus needs to be on the stage before the full polysemy. That is, given that metonymy is hard to apply here, what real world, linguistic and non-linguistic (situational) factors could lead to the sort of indeterminacy the construction needed for the dual interpretative potential to develop?

\subsection{Usage-based approaches}

In a construction grammar approach, constructions, are simple and complex form/function pairings of various types. ${ }^{53}$ There are no genetically inherited structures or operations like transformations as found in some other models of human linguistic knowledge. ${ }^{54}$ Constructions can be fully spelt out and specify the full form of a complex string, , like kicked the bucket to mean 'die' or they can relatively schematic and supply a basic pattern, like the English passive as subject $+\mathrm{BE}+$ past participle. Of course, we can have constructions that mix the two as well, such as the let alone construction in examples He isn't well known, let alone famous.

In a construction grammar approach, constructions do not occur in isolation either from usage event contexts, or from the larger constructions in which they are used. Croft and Cruse argue that in the interpretation of utterances "flexibility is necessary". ${ }^{55}$ This is because linguistic units are dependent on the frames, or situations, in which they occur; in other words, linguistic events arise from usage events. ${ }^{56}$ This view forms the foundation of the "usagebased" approach within a cognitive linguistics framework. ${ }^{57}$ A usage-based approach holds that language is dynamic and in a state of constant flux. Innovations, new form/function pairings, can occur due to some speaker driven motivation, such as increasing expressivity, a desire to be noticed ${ }^{58}$ or from variation in construal. ${ }^{59}$ They can also result from natural variation in the expression of experiences (see Croft, who argues against the weight attached to other explanations $)^{60}$ and from the indeterminate nature of (the perception of) reality and of the human actors within the usage event itself. Clearly, constructions at any level cannot be considered in isolation from the constructions in which they appear and from which they derive aspects of meaning. ${ }^{61}$

\footnotetext{
${ }^{53}$ Goldberg.

${ }^{54}$ See for example Chomsky, Aspects and Minimalist Program

${ }^{55}$ Croft and Cruse, 72.

${ }^{56}$ Langacker, Cognitive Grammar, 220.

57 See Croft, Radical Construction Grammar; Langacker, Foundations of Cognitive Grammar: Volume 1; Langacker, Cognitive Grammar.

${ }^{58}$ Haspelmath, "Why is Grammaticalization Irreversible?", 1043.

${ }^{59}$ Langacker, Cognitive Grammar.

${ }^{60}$ Croft, "Origins of Grammaticalization".

${ }^{61}$ Croft, Radical Construction Grammar, 92-8; Goldberg.
} 


\section{S. J. Disney}

On this view, existing constructions can be templates for the interpretation of novel utterances, i.e. a construction can "sanction", either partially or fully, a novel use. ${ }^{62} \mathrm{~A}$ conventionalisation process may then be triggered for a particular existing form, leading to a 'new' use for that form. This is the basis of analogy as it applies to language change. Underlying this is a process of coercion. Goldberg gives the example of causative "sneeze the foam off the cappuccino"; 63 no-one would argue that sneeze has "grammaticalised" into a caused motion verb, or has that as a sense that we could list in a dictionary. Instead, what occurs is that the normally intransitive verb sneeze, in this particular construction alone, gets a different construal; because the English Caused Motion construction as a whole implies a cause > effect event, the utterance with sneeze can be interpreted as instantiating this construction. This is not, at this point, a new 'sense' of sneeze. Many such constructions are hugely productive; the English |Passive, Ditransitive and tense/aspect constructions are simple example. Another is the passive NCI (nominativus-cum-infinitivo) construction. As claimed by Noël, a hearsay / evidential reading "is the default reading of passive matrices". ${ }^{64}$ It has a high type frequency, including supposed, and a high token frequency, especially in certain genres, like Journalism and Science writing. Disney shows how deontic BE meant to has developed a hearsay use (in British English, at least), by analogy to the Hearsay NCI. ${ }^{65}$ The development of a hearsay from a deontic construction shows that movement between the domains, at least in these agentless passive constructions, is possible. However, note that the $\mathrm{BE}$ meant to development does align with expected deontic > evidential/epistemic unidirectionality expectations.

(41) He's meant to be the sexiest man in America. (ICE-GB: sla 065 059)

To return to the BE supposed to question, Noël and van der Auwera ask how it could be that, given the high number of possible instantiations of the evidential NCI, "only one other pattern viz. be expected to, developed into a deontic construction?" 66 They argue that because deontic BE thought to does not exist, evidential be supposed to is a "doubtful source of the deontic construction". ${ }^{67}$ However, and in complete contrast to SUPPOSE in the same data, there are some potential active 'intend' examples for THINK, e.g. (42)-(43) below, but no passive ones.

(42) Madamoselle thought to go thither her self in person, to break off these Negotiations. (1676. a42275)

(43) When his locks were gone, he thought to go forth and shake himself as at other times. (1681. a51842)

\footnotetext{
${ }^{62}$ Langacker, Cognitive Grammar, 24.

${ }^{63}$ Goldberg, 42.

${ }^{64}$ Noël, "Passive Matrices", 276.

${ }^{65}$ Disney, "Reputed Sense of BE Meant To".

${ }^{66}$ Noël and van der Auwera, 616.

${ }^{67}$ Ibid., 617.
} 
In fact, such semantic scope appears to be less unusual than it at first seems to be; examples of PRETEND also bridge evidential, epistemic and deontic uses in the historical data e.g. (44)-(45). The default sense of PRETEND in Latin according to $\mathrm{OED}_{3}$ was a composition of pre+tend, i.e. before + tend, where tend is "to incline" or "move in a certain direction." It was borrowed as a composite, meaning 'claim', which later developed to 'falsely claim'. The Middle English Dictionary describes an 'intend' sense and a link to 'expect' as "4. To intend (sth. , to do sth.), propose, plan; prepare for (sth.); (b) refl. to expect (to do sth.)". Example (44) shows an 'intend' use.

(44) the Lacedemonyens assembled theyr counsayle, and caused it to be declared wyth loude voyce, that yf there were any parsonne that pretended to make any complaincte agaynst the Athenyans, he shulde speake publiquely, as the custome was. (1550. 13758)

Example (45) shows an 'intend' passive. The reiteration with would disallows an interpretation of 'feigned strike'. Such uses are rare indeed, but that does not mean they can be ignored.

For the Target (whose charge is onely to defend) is so great, that it may easily warde all edgeblowes, \& those chiefely which come from the knee vpwardes. Farther, when a blowe is pretended to be deliuered, it is manifest, that a thrust doth enter by a more narrowe straight than any edgeblowe doth. And therefore, when one woulde strike the enimie standing at the locke or lowe warde, he must remember that he approch as neere him as he may possible. (1594. a02044)

The final theoretical point to note is that in a construction grammar approach, not only are constructions tied to their usage events, but also that "no concept exists autonomously". ${ }^{6}$ Concepts are not randomly stored in the mind of the speaker/hearer, but form a "structured inventory" in taxonomic networks ${ }^{69}$. Crucially, when any particular concept is activated in the mind, related concepts are also (partially) activated. ${ }^{70}$ If, for example, I mention the word 'dog', then concepts like 'collar' and 'lead' are strongly activated, while 'mirror' is probably not activated. If I mention the concept 'instruction', the concepts 'tell', 'comply' and 'refuse' may be activated, while 'fly' is unlikely. On this view, although meaning is constructed in usage events, it is not random. Further, the constructed meaning is actually constrained by the structure of the conceptual network, i.e. by sense relations and by our experiences of prior usage. ${ }^{71}$ Thus, we find "links in a chain" during semantic change. That is, if a gram has meanings $\mathrm{A}, \mathrm{B}$ and $\mathrm{C}$, a leap from $\mathrm{A}$ to $\mathrm{C}$ maybe be very unlikely, whereas $\mathrm{A}>\mathrm{B}>\mathrm{C}$ in turn may be quite feasible. This is where metonymy comes in to language change: $\mathrm{A}$ and $\mathrm{B}$ may overlap in concept and so might B and C. A form may gain a meaning from part of a previous meaning. It does not follow that such a link exists between A and C. An extreme example of

\footnotetext{
${ }^{68}$ Croft and Cruse, 16.

${ }^{69}$ Ibid., 262-5; Langacker, Cognitive Grammar; Hoffmann and Trousdale, 4.

${ }^{70}$ Croft and Cruse, 292.

${ }^{71}$ See Croft, Radical Construction Grammar; van der Auwera, "Semantic Maps".
} 


\section{S. J. Disney}

this is the sense change of NICE from meaning 'stupid/foolish' to 'pleasant' over six hundred years of use through various senses like 'delicate' and 'fussy'. Each development takes a part of the previous meaning and this becomes the whole meaning. Where this becomes particularly interesting is that interaction between separate items in the inventory can occur; thus we have coercion and analogy. It here that the discussion returns to BE supposed to.

\subsection{The development of deontic BE supposed to}

Recall the view from Construction Grammar that constructional schemas act as templates for interpretation, e.g. "causative" sneeze above. The BE supposed to usage pattern strongly suggests that the deontic senses are not inherited directly from the historical lexical semantics of SUPPOSE. Instead, I argue that they arise from templates derived from existing (agentless) passive constructions. Therefore, firstly, evidence should be sought for the existence of a "deontic construction", a template with a passive form that acts as the basic sanctioning construction. Secondly, the particular aspect of the use of BE supposed to that allowed it to be sanctioned needs to be established.

With respect to the first of these questions, table 3 shows frequency rates found by WordSmith tools 5 for the pattern [BE *-ed to $+\mathrm{V}$ ] (where BE is all forms of BE and V is a verb) in the 1690s EEBO-TCP. This is a century prior to the development as claimed above, and from the 1750-99 part of the C18C corpus, which immediately predates the first possible examples in the data. The search results were manually edited so that they contain only infinitival to complements. Each verb is assigned a label according to the superordinate modality of its default semantic value, i.e. its main dictionary sense; $\mathrm{D}=$ deontic, $\mathrm{E}=$ epistemic, $\mathrm{H}=$ evidential/hearsay. I note that this lacks semantic precision and the results have not been filtered for potential polysemy, however the 'default' senses are by far the more frequent in every case, and the related senses tend to have the same modal domain anyway, with some exceptions as outlined above. The most frequent ten of these [BE $*$-ed] tokens are shown in table 3. Only passive $(\mathrm{P})$ reduced is outside this classification in the top tens.

Table 3 Top ten instantiations of $[\mathrm{BE} *$-ed to $+\mathrm{V}]$ from the specified corpora

Even this rather cursory table reveals an almost doubling of the token frequency in the use of the pattern $[\mathrm{BE} *$-ed + infinitival $t o]$ between the periods and that the majority are deontic. The other verbs outside the top ten, and the far more frequent irregular verbs with deontic senses such as MAKE, add significantly to this trend. Further, the top ten in 1690-99 account for $48 \%$ of the total instances of this pattern, while in the 1750-99 corpus they account for only $31 \%$. This indicates a large rise in type frequency for the basic passive pattern too. In diachronic construction grammar approaches, increases in type and token frequency for a pattern are indicative of constructionalisation, i.e. it is argued that a pattern can become a template with high enough use. ${ }^{72}$ I would add that the timing in the type and token frequency

${ }^{72}$ Fillmore, Kay, and O'Connor; Croft, Radical Construction Grammar; Goldberg; Bybee, Frequency of Use; Noël, "Diachronic Construction Grammar"; Fried. 
rises supports the dating for the innovation of deontic BE supposed to as being the very late eighteenth century, as suggested above. The situation therefore suggests that the linguistic conditions for a potential agentless passive infinitive construction with a deontic meaning to be become "constructionalised" did exist. Data from the BNC show that deontic examples in the $\mathrm{BE} *$ ed to form are now of much lower frequency and therefore a less powerful coercive force. It may be that sanctioning and coercion, i.e. a generalisation across constructions, is all that is required to account for this change, but a second point needs to be considered in a full usage-based account.

Noël and van der Auwera ask what is inherent in evidential BE supposed to that would predispose it to a deontic development which is not also inherent in BE thought to or other evidential NCIs. ${ }^{73}$ In other words, how would a metonymy work in one, but not the other? The answer to this question is clearly the existence of a future-oriented 'expected' sense for $\mathrm{BE}$ supposed to. It is clear from other constructions that the link between expectation and deontic modality is blurred or at best, overlapping. ${ }^{74}$ Alberti et al. discuss the rise of deontic meaning in a wider context connected to expectations. ${ }^{75}$ There is also a strong link between expressions of wishes, desires and expectations, and implicatures of obligation, especially where face concerns in the discourse context require expressions to be less direct. ${ }^{76}$ These supply the bridging context motivations, as seen above. For example, the $O E D_{3}$ says of the imperative in (46) that suppose introduces "a hypothetical statement or case".

(46) Suppose here hijs o iustyse, God and truwe. (c1315. SHOREHAM VII. 44)

Suppose here is of justice God and true.

"Assume God's justice is true."

This imperative is in effect an instruction to the reader to hold an opinion, in the current discourse space, where a requirement exists for the view to be held as being "true". Crucially, 'requirement' is a deontic value. In other examples in the data, the construction " $\mathrm{B}$ supposes A" means "for B to be the case, it is necessary for A to be the case", which is clearly a deontic gloss, at least potentially. The explanation for the deontic development of $\mathrm{BE}$ supposed to would therefore seem to lie in the connection, with BE expected to, as argued by Traugott, Visconti and Moore. ${ }^{77}$

For me, the explanation therefore lies not in some Active Voice 'intend' sense of SUPPOSE, an extension THINK seems to have. Instead it lies in the original 'expect' sense, which THINK does not. Further, Noël and van der Auwera argue that deontic BE expected to is not a grammaticalisation of evidential BE expected to, but is the result of an inference chain. ${ }^{78}$ One potential inference chain involves the expression of beliefs about duties and obligations. In real use, the boundary between necessity and possibility is quite fluid in actual usage

\footnotetext{
${ }^{73}$ Noël and van der Auwera.

${ }^{74}$ Cf. van der Auwera and Plungian, "Modality’s Semantic Map".

${ }^{75}$ Alberti et al.

${ }^{76}$ I thank an anonymous reviewer for noting this.

${ }^{77}$ Traugott, "Rise of Epistemic Meanings"; Visconti; Moore.

${ }^{78}$ Noël and van der Auwera.
} 


\section{S. J. Disney}

events, especially where negation is concerned, and especially where reports are involved. So with BE supposed to we have an agentless passive construction that on the one hand reports beliefs and on the other reports requirements. We have seen above that the bridging examples are where a belief is expressed in the context of duties and obligations. Again, face concerns may be a motivation for an indirect expression of obligation, particularly where a power imbalance exists between interlocutors. As an illustration, consider again (38) above, partially reproduced as (47), to see how these two meanings of BE supposed to could even feasibly exist simultaneously, i.e. the clergy were both assumed and obliged to give up family life in order to carry out their clerical duties.

That time which the married clergyman devotes to the care of his family, was supposed to be given up to the duties of charity and exercises of religion. (1829. The North American Review. vol XXIX p. 270)

Another inference chain concerns cases where an action is expected (by an offstage authority) to occur, and where that expectation equates to a desired outcome: where the higher power desires a future action of someone, they would expect it to occur because they have the power to make it so. What is more, people know this and thus it forms the background to the interaction, and can be exploited by interlocutors. The reporting interlocutor may feel a need to avoid a face threatening act or distance themselves from the obligation/instruction, and hence use a more indirect form. This allows the instructee to draw an inference that the obligation exists with no need for the intermediary to actually state it, even if they were in fact the source of the obligation. This is part of the motivation for using an agentless passive in the first place of course, i.e. to obfuscate agency. The points discussed above about THINK are the only argument against the same chain allowing the 'expect' sense of BE supposed to from itself extending to a deontic too.

The final point to raise concerns frequency. At the same time as the schematic deontic construction posited above increased in both type and token frequency, the passive hearsay $\mathrm{BE}$ supposed to also became higher in token frequency. This increases the potential for indeterminate usage-events to arise. The question is, why would the frequency of deontic events rise so rapidly? Although it is necessarily conjectural, it is the wider social discourse context, and the relative roles of the participants, that could offer a clue. Lack of space prohibits lengthy discussion, but historians have long noted that duty and obligations were integral, if not a driving force, to the British Empire. ${ }^{79}$ These prevailing social conditions would have encouraged a rise in deontic-type contexts and a corresponding rise in reports of situations, orders, expectations and so on; note that the data do contain a lot reference to "duty". Verhagen discusses a similar effect with Dutch causatives, making a link between cultural norms and use of certain constructions. He states that "the diminishing role of authority in the texts is a major factor in the decrease of doen". ${ }^{80}$ Note that in a military chain of command, where duties are paramount, a 'reported expectation' is unlikely to be something that an authority does not want or expect to occur, unless it is expressed as a

\footnotetext{
${ }^{79}$ See e.g. Webster; Ferguson.

${ }^{80}$ Verhagen, 274.
} 
negative, when it would be interpreted as a prohibition. Not coincidently, this could also explain why BE supposed to has a different interpretation in negatives to the other, more lexical, deontic passives like obliged and required (see Disney forthcoming).

\section{Conclusion}

This paper has discussed problems with examples that have been used to argue for a particular explanation of how the BE supposed to deontic sense arose. The problematic BE supposed to developmental path has been accounted for in a usage-based perspective without recourse to any more borrowed meanings than those reported by Traugott. ${ }^{81}$ The development has been argued to have occurred based on a metonymy along with a sanctioning / coercion effect. I have argued for the existence of a passive deontic NCI construction, which mirrors the passive hearsay NCI described by Noël. ${ }^{82}$ The explanation fits a usage-based construction grammar model in two critical ways; first, the increase in deontic usage events means that non-linguistic contexts, and prevailing social factors, are incorporated. I acknowledge that more detailed work is needed before firm conclusions can be made about the constructional status of a 'deontic NCI', however, I have shown how it was possible that people were able to interpret BE supposed to as instantiating this proposed template construction by appealing only to well understood pragmatic processes and effects. Second, linguistically, BE supposed to is not treated in isolation from similar constructions in the semantic network. In fact, such is the convergence in events and contexts that led to this development, it is hardly surprising that such a development is not widely reported in other languages. Clearly, the point at which BE supposed to was initially 'reinterpreted', in the more indeterminate contexts, can be viewed as a pre-grammaticalisation phase. In terms of research into this type of process, I would argue that it is crucial to look elsewhere in the existing construction network for sanctioning potential before positing problematic additional inherited senses for words.

ABBREVIATIONS

$\begin{array}{ll}\text { BNC } & \text { British National Corpus } \\ \text { CxG } & \text { Construction Grammar } \\ \text { CL } & \text { Cognitive Linguistics } \\ \text { EEBO-TCP } & \text { Early English Books Online - Text Creation Partnership (phase 1) } \\ \text { ICE-GB } & \text { International Corpus of English - Great Britain } \\ \text { NCI } & \text { nominativus cum infinitivo } \\ \text { OE } & \text { Old English } \\ \text { OED } & \text { Oxford English Dictionary } \\ \text { PDE } & \text { Present Day English } \\ \text { SMCH } & \text { Semantic Map Connectivity Hypothesis. }\end{array}$

\footnotetext{
${ }^{81}$ Traugott, "Rise of Epistemic Meanings".

${ }^{82}$ Noël, "Passive Matrices".
} 


\section{S. J. Disney}

\section{References}

Alberti, Marco, Marco Gavanelli, Evelina Lamma, Paola Mello, Paolo Torroni, and Giovanni Sartor. "Mapping Deontic Operators to Abductive Expectations". Computational and Mathematical Organization Theory 12, no. 2 (2006): 205-25.

Berkenfield, Catie. "Pragmatic Motivations for the Development of Evidential and Modal Meaning in the Construction 'Be Supposed to X'.” Journal of Historical Pragmatics 7, no. 1 (2006): 39-71.

Biber, Douglas, Stig Johansson, Geoffrey Leech, Susan Conrad, and Edward Finegan. Longman Grammar of Spoken and Written English. Harlow, UK: Longman, 1999.

Bybee, Joan L. Frequency of Use and the Organization of Language. New York: Oxford University Press, 2007.

Bybee, Joan L., Revere D. Perkins, and William Pagliuca. The Evolution of Grammar. Chicago: University of Chicago Press, 1994.

Chomsky, Noam. The Minimalist Program. Massachusetts, US: MIT Press, 1995.

- - Aspects of the Theory of Syntax. Massachusetts, US: MIT Press, 1965.

Croft, William. Explaining Language Change: An Evolutionary Approach. Harlow, UK: Pearson Education, 2000.

- - Radical Construction Grammar: Syntactic Theory in Typological Perspective. Oxford: Oxford University Press, 2001.

- - "The Origins of Grammaticalization in the Verbalization of Experience." Linguistics 48, no. 1 (2010): 148.

Croft, William, and D. Alan Cruse. Cognitive Linguistics. Cambridge: Cambridge University Press, 2004.

Disney, Stephen. "Blended Constructions and Emerging Modals." Paper presented at the 5th UK Cognitive Linguistics Conference (UK-CLC5), Lancaster, UK, July 29-31, 2014.

- - "Evidentiality and Modality in English: The Theory and Practice of Establishing Evidential Constructions." Unpublished PhD thesis, Lancaster University, UK, 2012.

- - "The Reputed Sense of BE Meant To: A Case of Gradual Change by Analogy." In Synchrony and Diachrony: A dynamic interface, edited by Anna Giacalone Ramat, Caterina Mauri, and Piera Molinelli, 105-24. Amsterdam: John Benjamins, 2013.

Ferguson, Niall. Empire: the Rise and Demise of the British World Order and the Lessons for Global Power. London: Allen Lane, 2002.

Fillmore, Charles J., Paul Kay, and Mary Catherine O'Connor. "Regularity and Idiomaticity in Grammatical Constructions: The Case of Let Alone." Language 64, no. 3 (1988): 501-38.

Fischer, Olga. "Cognitive Iconic Grounding of Reduplication in Language." In Semblance and Signification, edited by Pascal Michelucci, Olga Fischer, and Christina Ljungberg, 55-81. Amsterdam: John Benjamins, 2011.

Fried, Mirjam. "Construction Grammar as a Tool for Diachronic Analysis." Constructions and Frames 1, no. 2 (2009): 261-90.

Gisborne, Nikolas. The Event Structure of Perception Verbs. New York: Oxford University Press, 2010.

Goldberg, Adele E. Constructions at Work: The Nature of Generalization in Language. Oxford: Oxford University Press, 2006.

Haspelmath, Martin. "On Directionality in Language Change with Particular Reference to Grammaticalization." In Up and down the Cline: The Nature of Grammaticalization, edited by Olga Fischer, Muriel Norde, and Harry Perridon, 17-44. Amsterdam: John Benjamins, 2004.

- - "Why is Grammaticalization Irreversible?" Linguistics 37, no. 6 (1999): 1043-68.

Heine, Bernd. "On the Role of Context in Grammaticalisation." In New Reflections on Grammaticalization, edited by Ilse Wischer and Gabriele Diewald, 83-101. Amsterdam: John Benjamins, 2002.

Heine, Bernd, and Tania Kuteva. World Lexicon of Grammaticalization. Cambridge: Cambridge University Press, 2002.

Hoffmann, Thomas, and Graeme Trousdale. "Variation, Change and Constructions in English." Cognitive Linguistics 22, no. 1 (2011): 1-23.

Hopper, Paul J., and Elizabeth C. Traugott. Grammaticalization. Cambridge: Cambridge University Press, 2003. 
Krug, Manfred G. Emerging English Modals: A Corpus-based Study of Grammaticalization. Berlin: Walter de Gruyter, 2000.

Langacker, Ronald W. Cognitive Grammar: A Basic Introduction. Oxford: Oxford University Press, 2008.

- - Foundations of Cognitive Grammar. Vol. 1. Theoretical Prerequisites. Stanford, CA: Stanford University Press, 1987.

- - “On Subjectification and Grammaticization." In Discourse and Cognition: Bridging the Gap, edited by Jean-Pierre Koenig, 71-89. Stanford, CA: CSLI Publications, 1998.

Moore, Colette. "The Spread of Grammaticalized Forms: The Case of Be+Supposed To." Journal of English Linguistics 35, no. 2 (2007): 117-31.

Noël, Dirk. "Diachronic Construction Grammar and Grammaticalization Theory." Functions of Language 14, no. 2 (2007): 177-202.

- - "The Passive Matrices of English Infinitival Complement Clauses: Evidentials on the Road to Auxiliarihood?" Studies in Language 25, no. 2 (2001): 255-96.

Noël, Dirk, and Johan van der Auwera. "Revisiting Be Supposed To from a Diachronic Constructionist Perspective." English Studies 90, no. 5 (2009): 599-623.

Norde, Muriel. Degrammaticalisation. Oxford: Oxford University Press, 2009.

OED online. 2009. Oxford University Press. http://www.oed.com/ (Accessed 1/4/2012).

Palmer, Frank. "Modality in English: Theoretical, Descriptive and Typological Issues." In Modality in Contemporary English, edited by Roberta Facchinetti, Manfred G. Krug, and Frank Robert Palmer, 117. Berlin: Walter de Gruyter, 2003.

Quirk, Randolph, Sidney Greenbaum, Geoffrey Leech, and Jan Svartvik. A Comprehensive Grammar of the English Language. London: Longman, 1985.

Rosenbach, Anette. "The English S-genitive: a Case of Degrammaticalisation?" In Up and down the Cline: the Nature of Grammaticalization, edited by Olga Fischer, Muriel Norde, and Harry Perridon, 73-96. Amsterdam: John Benjamins, 2004.

Sutherland, K. "Interview". http://www.chronicle.com (accessed 09 June 2012).

- - "News Story". http://www.ox.ac.uk/media/ (accessed 9 June 2012).

Sweetser, Eve. From Etymology to Pragmatics: Metaphorical and Cultural Aspects of Semantic Structure. Cambridge: Cambridge University Press, 1991.

The Middle English Dictionary. 2001. University of Michigan. http://quod.lib.umich.edu/m/med/ (accessed 1/4/2012).

Traugott, Elizabeth C. "On the Rise of Epistemic Meanings in English: An Example of Subjectification in Semantic Change." Language 65, no. 1 (1989): 31-55.

Traugott, Elizabeth C., and Graeme Trousdale, eds. Gradience, Gradualness and Grammaticalization. Amsterdam: John Benjamins, 2010.

Van der Auwera, Johan. "More Thoughts on Degrammaticalization." In New Reflections on Grammaticalization, edited by Ilse Wischer and Gabriele Diewald, 19-29. Amsterdam: John Benjamins, 2002.

- - "Semantic Maps, for Synchronic and Diachronic Typology." In Synchrony and Diachrony: A dynamic interface, edited by Anna Giacalone Ramat, Caterina Mauri, and Piera Molinelli, 153-76. Amsterdam: John Benjamins, 2013.

Van der Auwera, Johan, and Vladimir A. Plungian. "Modality's Semantic Map.” Linguistic Typology 2, no. 1 (1998): 79-124.

Verhagen, Arie. "Interpreting Usage: Construing the History of Dutch Causal Verbs." In Usage-based Models of Language, edited by Michael Barlow and Suzanne Kemmer, 261- 86. Stanford, CA: CSLI Publications, 2000.

Visconti, Jacqueline. "Conditionals and Subjectification: Implications for a Theory of Semantic Change." In $U p$ and down the Cline: the Nature of Grammaticalization, edited by Olga Fischer, Muriel Norde, and Harry Perridon, 169-92. Amsterdam: John Benjamins, 2004.

Webster, Anthony. The Debate on the Rise of the British Empire. Manchester: Manchester University Press, 2006. 


\section{S. J. Disney}

Xiao, Richard, Tony McEnery and Yufang Qian. "Passive constructions in English and Chinese A corpus-based contrastive study." Languages in Contrast 6, no. 1, (2006). 109-149).

Ziegeler, Debra. "On the Generic Origins of Modality in English.” In English Modality in Context: Diachronic Perspectives, edited by David Hart, 33-69. Bern: Peter Lang, 2003. 